\title{
ASSESSMENT OF NATURAL REGENERATION OF DIFFERENT FORMS OF GAPS IN ATRUSH FOREST
}

Muzahim S. Al-Bek ${ }^{1}$, Muhammad Y. Al-Allaf ${ }^{1}$, Muhannad Abdel-Qader ${ }^{2}$

${ }^{1}$ Forestry department, College of Agriculture and Forestry, Mosul University, Iraq.

${ }^{2}$ Nineveh Department of Agriculture, Mosul, Iraq.

Email: muzahim_saeed@uoimosul.edu.iq

\begin{abstract}
Atrush Forest is a mixed forest that contains many types of forest trees and shrubs, and the dominant species in these forests (Pinus brutia Ten., Querecus sp., Crataqus ozaralus, Juniperus oxycedrus, Rhus coriaria, Prunus amycdalus, Ficus carica L. and Plautus spina-christi), the total area of the study area was determined (126.1821) hectare, (1786) gaps were fixed, classified into four categories, measurements were taken of the crowns and the total height of the surrounding trees that make up the circumference of the gap. As for the gap area, use the ellipse formula. It was found that the numbers of small gaps come in the forefront for each category $(X<200) \mathrm{m}^{2}$ and $(200<\mathrm{X}<400) \mathrm{m}^{2}$ where the number of gaps in the first category $(X<200)(855)$ was a problem gap of $48 \%$ of the total gaps, while the second category followed $(200<X<400)$, in which the number of gaps was (444) gaps and constituted $(25 \%)$, while the third category $(400<X<600)$, the number of gaps was (171) gaps formed by that $(10 \%)$ of the total gaps, while the number of gaps in the fourth and large category ( $X>600$ ) was (316) gaps, and 17\% of the total gaps formed, while the shapes for the gaps were the triangular, oval, regular, and irregular shape Regular proportions $(6,30,37$ and $27 \%)$ respectively, and that the ellipse and regular form $(67 \%)$ of total space. As for the gaps with areas $(400<\mathrm{X}<200) \mathrm{m}^{2}$ where the triangular, oval, regular and irregular shapes form the proportions $(9,28,39,24 \%)$ respectively, we find that the oval and regular forms are a total of $(67 \%)$ of the areas of the second category, while the gaps with areas $(600<\mathrm{X}<400) \mathrm{m}^{2}$, the triangular, oval, regular and irregular shapes formed the proportions $(13,25,40,22 \%)$ respectively, and the oval and regular forms formed $65 \%$ of the areas of the third category. While we find that the large gaps whose area is greater than $(600>\mathrm{X}) \mathrm{m}^{2}$, we find that the triangular, oval, regular and irregular oval shapes formed proportions $(13,18,53,16 \%)$, respectively, and that the sum of the ratios The oval and regular forms of the fourth area category are $(71 \%)$, and this indicates that the oval and regular forms are the most common forms in the gaps, and there is no doubt that regular forms are prevalent at the site of the study and formed (17\%) of the total gaps.

Keywords: Natural forests, Natural regeneration, Biodiversity, Forest gaps.
\end{abstract} Received:13/8/2020, Accepted: 16/10/2020

\section{INTRODUCTION}

Natural forests are distributed in different places from the surface of the earth with different types of trees and according to the environmental conditions of these sites, so we find many types of trees that grow mixed with other types coexist with

The research is part of Ph.D. of $3^{\text {rd }}$ Other 
them naturally, and these forests are used for various productive and environmental purposes (Myers, 1997). It is considered to be in the region of Atrush, in the north of Iraq, southeast of Dohuk governorate, where there are natural forests made of many species, such as Pinus brutia Ten., Oak Querecus sp., Crataqus ozaralus, Juniperus oxycedrus, Rhus coriaria, Prunus amycdalus, Ficus carica L. and Plautus spina-christi.

Pawlikowski et al. (2019) has stated that knowing how tree groups and gaps form is key to managing unequal forests by identifying changes in the tree group and the spatial composition of the gap and abundance of species.

Forest canopy disruption can lead to changes in the abundance and richness of pent-up plant species, and investment is described as a disorder in the forest ecosystem. Kathke (2010) has indicated that the presence of gaps increases the heterogeneity of forest composition by creating new local sites, and canopy gaps are not fixed but change their area and shape over time as they narrow and gradually close through the horizontal growth of adjacent trees. The gap or vertical growth of small initiatives and growing juveniles in the gap, where small gaps in particular close within a few years, while large gaps often widen as a result of the death of neighboring trees, and this leads to a constant change in the availability of light for the lower layers of the coronary canopy and regeneration. While Adele et al. (2014) emphasized the role of gaps as they play an important role in the forest environment, help preserve biological and environmental diversity, affect nutrient cycles, and maintain the complex composition of forests, and over the past thirty years many Research describing the movement of the gap. Here we compile the current understanding of the movement of the gap and through which the gap affects the composition of the forests, where the area of the gaps leads to important changes in factors such as light intensity, soil moisture and soil biological properties that affect the regeneration of tree types and differ in gaps of different areas.

The gaps that arise in the forests are an environment suitable for the occurrence of natural regeneration and reconfiguration and installation of the tree from the early stages of it, and there are natural methods that help in that, including the occurrence of gaps and are a result of doing natural disturbances that occur in forests such as fires, winds, storms, diseases, insect injuries or reaching physiological age For trees (Van der Meer and Bongers, 1996; Obiri and Lawes, 2004).

Accordingly, it was necessary to study this phenomenon and determine its characteristics and know how these gaps are and how to fill them and what impact this has on the composition of the forest and what are its results, using many methods and scientific methods of statistical aspects and advanced models through which to describe the current state of the forest and estimate what will lead to it In future time periods, and the extent of the impact of environmental conditions such as climate, temperatures, humidity, amount of precipitation, wind and lighting, as well as ground effects of soil inclination and trends, in the process of regeneration and development, filling of gaps and other composition (Van der Meer et al., 1994), this study aims to number and type of gaps in the forest on the various spaces, in 
addition to determine the area and shape of the gaps in the forest gaps. Determine coronary coverage in species gaps for seedlings and Sapling groups.

\section{MATERIALS AND METHODS}

The study was conducted on forests in the Atrush district in the southeast of Dohuk governorate in northern Iraq, the Atrush Mountains, which includes several types of needle trees, mainly pines and juniper, and broad-leaved species such as oak and hawthorn, the study area is located between longitudes $\left(43^{\circ} 20^{\prime} 20^{\prime \prime} \mathrm{E}-43^{\circ}\right.$ $\left.21^{\prime} 40^{\prime \prime} \mathrm{E}\right)$ and latitude ( $\left.36^{\circ} 51^{\prime} 20^{\prime \prime} \mathrm{N}-3652^{\prime} 10^{\prime \prime} \mathrm{N}\right)$, with an altitude of from sea level ranging between (780-950) $\mathrm{m}$, and an area of (126.182) hectares. The mountainous area of Atrush forest enjoys the spread of various vegetation, and we notice grasses, weeds and other pastoral plants, as well as wild and broad-leaved forests, and sometimes there are mixed spots of both broad-leaved and wild types, and the most important types of trees that spread there are Pinus brutia Ten., Quercus infectoria, and Junipours axycedrus and Rhus coriaria, hawthorn (Crataqus ozaralus), wild figs (Ficus carica L.), almonds (Prunus amycdalus), and Christ prick (Plaututs spina-christi).

After classifying the statement and knowing the area of the forest, we can identify the different gaps in the study site. To assess the accuracy of the gap map, field observations of a number of gaps can be used as site samples, with a visual examination of the site image by a false film (RGB) in false colors (red, green, and blue) and matching them, one hundred percent of the gaps visited are categorized correctly and this is what he did (Garbarino et al., 2011). To identify the different gaps in the study site, we used Arc Map, and by this method, all gaps were identified for the forest in terms of shape. In terms of calculating the area for the gap, it was through the use of the measuring ruler, and through it we can choose the unit of measurement that we want to calculate the area (square meters, hectares or any other area unit). Where a square meter unit was chosen and by the indicator the gap area can be determined by moving it over the entire circumference of the gap to be measured and when the drawing is finished, we press (Double Calc) on the indicator and the area appears directly to us and from the repetition of this mechanism on all the gaps.

Those that were previously drawn to the forest were able to estimate the areas for the various gaps (Betts et al., 2005). The gap areas spread in the study area of the mixed Atrush forest were calculated and categorized according to the area categories and their frequency was calculated as in Table (1).

Table (1): Categories of spaces for the gaps and their frequency for the study area in the mixed natural forest of Atrush

\begin{tabular}{|c|c|c|}
\hline Area gaps class & Frequency & Area $\left(\mathrm{m}^{2}\right)$ \\
\hline $\mathrm{X}<200$ & 855 & 21.530 \\
\hline $200<\mathrm{X}<400$ & 444 & 118.508 \\
\hline $400<\mathrm{X}<600$ & 171 & 82.680 \\
\hline $\mathrm{X}>600$ & 316 & 564.458 \\
\hline Total & 1786 & 787176 \\
\hline
\end{tabular}


As for the estimation of the circumference, we follow the same previous steps to calculate the area, but when we reach the choice of the type of scale, we choose the distance (instead of the area), and thus we get the circumference of the gap as well. After repeating this process on all Gaps We have estimated the shape, area, and circumference of each gap located within the study area, as they gave different shapes, as shown in Figure 1.

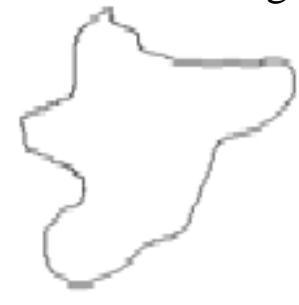

irregular

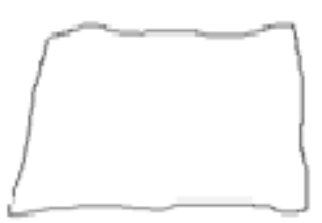

Regular

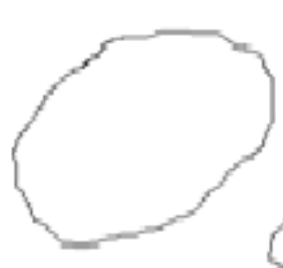

oval

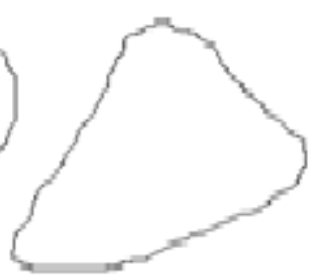

triangle,

Figure (1). Drawings of triangle, quadrilateral, oval, and irregular gaps.

The process of preparing the network is necessary to estimate the areas occupied by the different elements of the components of the gaps, where the edge of the gap is defined as the vertical projection of the crowns of the canopy trees surrounding the gap on the ground, on this basis the coronary canopy is inventoried during certain time periods after preparing a network $(5 \times 5) \mathrm{M}$, Umbrella sectors are divided for the purpose of inventorying gaps (Numata et al., 2006; Dusan et al., 2007; Zeibig et al., 2005).

\section{RESULTS AND DICUSSION}

Natural factors have a significant impact on the forest ecosystem and its development. The spread of species and natural regeneration and full of gaps and tree-free stains affect and are affected by this. By analyzing the temporal characteristics and trends of the movement of the gap and its relationship to climate, the presence of gaps leads to an increase in the heterogeneity of the forest composition through the establishment of sites. A new locality also showed an increase in the movement of the gap over time, which may have a direct effect on an increase in average temperatures or an indirect effect of an increase in disease damage caused by this (Kathke, 2010).

The area of the gap ranged from the small (62) square meters formed by one tree to the middle gap (472) square meters formed by a group of trees, most of the identified gaps were small, indicating that they occur more frequently than large gaps (Zeibig et al., 2005). This description corresponds to the areas and frequency of gaps in the study area in the mixed Atrush forest.

The movement of gaps and the mechanism of their evolution and origin in the forests, in terms of their numbers, shapes, and the areas that they form in the Atrush region, which naturally spread and contain various types of gaps (Zeibig, et al., 2005), were divided according to their areas into four categories (Amiri et al., 2015) As shown in Figure (2). 


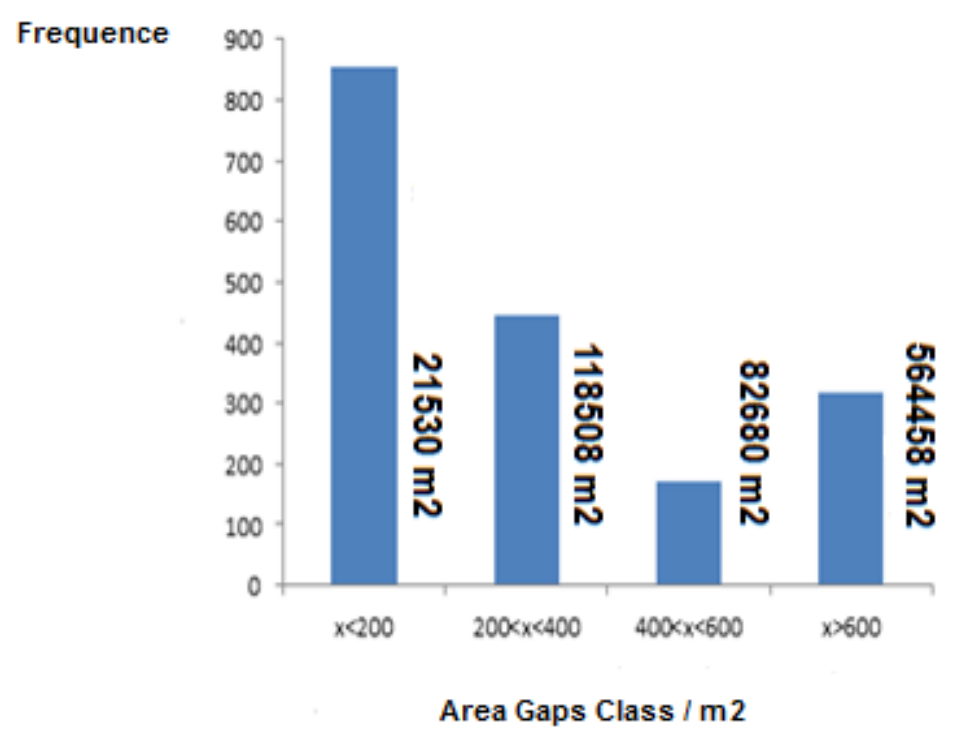

Figure (2). Distribution of gaps in the area categories and their frequency for the study area in the mixed Atrush forest.

It is clear from Figure (2) that the total area of the gaps was $(787176) \mathrm{m}^{2}$, and that the numbers of large gaps with areas greater than $(x>600) \mathrm{m}^{2}$ are of the least frequent (Indra and Per Christer, 2009; De Lima, 2005; Amiri et al., 2015), but it occupies an area of $(564.458) \mathrm{m}^{2}$ and constitutes a percentage of $(71 \%)$ of the total area of total gaps spread in the study area. When the category of small gaps with an area less than $(\mathrm{X}<200) \mathrm{m}^{2}$ is more frequent (Sapkota, and Odén, 2009; Ander et al., 2005) which occupies an area of $(21530) \mathrm{m}^{2}$ problem ratio $(3 \%)$ of the total gap area. As for the gaps whose area category $(400<\mathrm{X}<200) \mathrm{m}^{2}$, its area was (118508) $\mathrm{m}^{2}$ and constituted $(15 \%)$ of the total area of the total gaps, while the gaps whose category area of $(600<X<400) \mathrm{m}^{2}$ formed). It occupies an area $(82680)$ square meters of the total area of the total gaps, and these are calculated with the large gaps that are affected by social and community factors that affect the forest cover of the site (Amiri et al., 2015).

Accordingly, we see that the process of closing gaps with categories of area $(200<X)$ and $(400<X<200) \mathrm{m}^{2}$ is faster, with areas of $(3$ and $15 \%)$, respectively, than the total gaps area.

This is due to the ability of maternal trees to produce and sow seeds and create a suitable environment for on-site regeneration without human intervention, and that natural regeneration occurs through seedlings (Pawlikowski et al., 2019; Busing, 1994).

While the largest gaps in the last two categories are expected to be partially filled, or by human intervention either by sowing seeds or planting seedlings to help close the gaps faster (Pawlikowski et al., 2019). The existence of gaps in different areas may provide varying levels of resources that benefit different types, whether within gaps or between gaps, allowing species to coexist stable (Schnitzer et al., 2008).

The distribution of gaps in the study site was different in form, as they appeared in a triangular, oval, regular and irregular shape (De Lima et al., 2013). So 
the difference in the shapes between the gaps with different categories of areas and the same category of area, and this is what was estimated in Table (2).

Table (2): Shows the numbers and shapes of gaps and their distribution according to their area categories for the study area in the mixed Atrush forest.

\begin{tabular}{|c|c|c|c|c|c|}
\hline \multirow{2}{*}{ Total } & \multicolumn{4}{|c|}{ Shape } & \multirow{2}{*}{ Gaps area } \\
\cline { 2 - 5 } & Irregular & Regular & Oval & Triangle & \\
\hline 855 & 230 & 318 & 256 & 51 & $\mathrm{X}<200$ \\
\hline 444 & 106 & 175 & 125 & 38 & $200<\mathrm{X}<400$ \\
\hline 171 & 38 & 68 & 43 & 22 & $400<\mathrm{X}<600$ \\
\hline 316 & 52 & 166 & 57 & 41 & $\mathrm{X}>600$ \\
\hline 1786 & 426 & 727 & 481 & 152 & Total \\
\hline
\end{tabular}

We find that Table (2) determines the numbers of gaps and their shapes for each area category, and from it we note the numbers of small gaps that come at the forefront for each category $(\mathrm{X}<200) \mathrm{m}^{2}$ and $(200<\mathrm{X}<400) \mathrm{m}^{2}$ where the number of gaps in the first category $(X<200)(855)$ is a problem gap $(48 \%)$ of the total gaps, followed by the second category $(200<X<400)$ in which the number of gaps was (444) and formed a ratio of $(25 \%)$, while the third category $(400<X<600)$, as the number of its gaps was (171) a problem formed by that (10\%) of the total gaps, while the number of gaps in the fourth and large category ( $X>600)$ was (316) a gap and a percentage (17 \%) of Total Gaps (Sapkota and Odén, 2009; Zeibig et al., 2005).

As for the forms of gaps, we find that the regular shape constitutes a percentage of (41\%), which is the highest percentage among the total forms, as this ratio was distributed among the different area categories for gaps, and we find in the small area category $(\mathrm{X}<200) \mathrm{m}^{2}$ the proportion of $(44 \%)$. While in the second category of area $(200<X<400) \mathrm{m}^{2}$, its percentage was $(24 \%)$, while in the third category of area $(400<X<600)$, it formed a percentage $(9 \%)$, while in the fourth area category They are large areas $(X>600)$ percent $(23 \%)$.

While we find the oval shape the second form, which is $(27 \%)$ of the forms of total gaps, distributed among the space categories for the gaps, we find in the category of small area $(\mathrm{X}<200) \mathrm{m}^{2}$ the form of the ratio $(53 \%)$, while in the second category $(200<\mathrm{X}<400) \mathrm{m}^{2}$ was $(26 \%)$, but in the third category of area $(400<\mathrm{X}<600) \mathrm{m}^{2}$ was the proportion $(9 \%)$, while it was formed in the fourth area category which is large areas $(X>600) \mathrm{m}^{2}(12 \%)$.

As for the irregular shape, it constituted (24\%) of the total forms of total gaps and was distributed among the space categories for gaps by $(54 \%)$ in the small area category $(X<200) \mathrm{m}^{2}$, and $(25 \%)$ in the second area category $(200<\mathrm{X}<400) \mathrm{m}^{2}$, while it was in the third area $(400<X<600) \mathrm{m}^{2}(9 \%)$, and it formed in the fourth category of the area which are large areas $(X>600) \mathrm{m}^{2}$ ratio $(12 \%)$.

While we find that the triangular shape formed a percentage $(8 \%)$ of the total shapes of gaps distributed in different proportions over the space categories for the gaps, where we find in the small area category $(X<200) \mathrm{m}^{2}$ the shape of the ratio $(34 \%)$, and in the second area category $(200<\mathrm{X}<400) \mathrm{m}^{2}$ ratio $(25 \%)$, while in 
the third area category $(400<\mathrm{X}<600) \mathrm{m}^{2}$ format ratio $(14 \%)$, and a form in the fourth category of area which is large areas $(X>600) \mathrm{m}^{2}$ ratio $(27 \%)$.

From the foregoing, we find that the regular and oval shape formed the largest percentage of shapes, where their proportions were (41 and $27 \%$ ) respectively, which means a total of $(68 \%)$ of the forms of total gaps. This means that the regular and oval shape of the gaps are the predominant forms in the forests, And that the determination of simple geometric shapes varies according to the type, age, and area of the forest (De Lima et al., 2013). Also, these shapes showed the random distribution of the shape of the gap over the gap areas (Dusan, et al., 2007). These numbers and shapes were determined in the form of graphs to illustrate the extent of the apparent contrast of different The spaces for the gap are as shown in Figure 3.

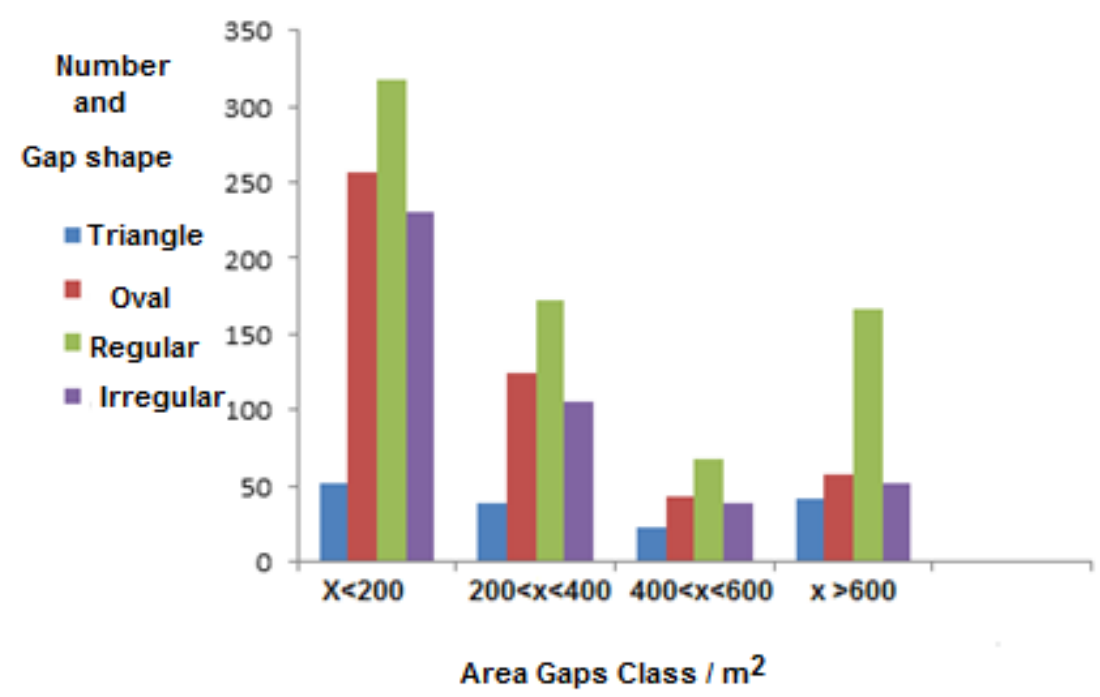

Figure (3). Shows the different shapes for the gap areas categories for the mixed Atrush forest.

The numbers of gaps and their distribution to their area categories may not give us clear visions of the areas occupied by each shape for a single area category, so we have distributed the spaces on the forms for one category and know the percentage of what forms from that category constitute.

The spaces for the first category $(X<200)$ find that the triangular, oval, regular and irregular shape form the proportions $(6,30,37$ and $27 \%)$, respectively, and that the oval and regular forms are $(67 \%)$ of the first category spaces. This is consistent with what he indicated (De Lima et al., 2013).

This is repeated with gaps with areas $(400<\mathrm{X}<200) \mathrm{m}^{2}$ where the triangular, oval, regular and irregular shapes form the proportions (9, 28, 39 and $24 \%$ ) respectively, and we find that the oval and regular shape forms a total of $(67 \%)$ of the second category areas. As for the gaps with areas $(600<X<400) \mathrm{m}^{2}$, the triangular, oval, regular and irregular shapes formed the proportions $(13,25,40$ and $22 \%$ ) respectively, and the two oval forms The regular team constituted $(65 \%)$ of the third category.

While we find that the large gaps whose area is greater than $(600>\mathrm{X}) \mathrm{m}^{2}$, we find that the triangular, oval, regular and irregular oval shapes formed proportions $(13,18,53$ and $16 \%)$, respectively, and that the sum of the ratios. The oval and 
regular forms of the fourth area category are $(71 \%)$, and this indicates that the oval and regular forms are the most common forms in the gaps, and there is no doubt that regular forms are prevalent in the study site (Guo et al., 2019; Pawlikowski et al., 2019; De Lima et al., 2013).

$$
\begin{aligned}
& \text { تقييم التجديد الطبيعي لأشكال مختلفة من الفجوات في غابة آتروش }
\end{aligned}
$$

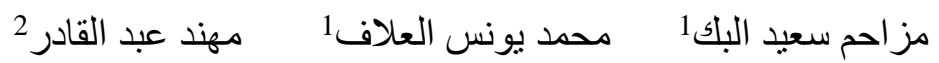

$$
\begin{aligned}
& 1 \text { قسم الغابات/ كلية الزر اعة و الغابات/ جامعة الموصل العلافل } \\
& 2 \text { دائرة زر اعة نينوى/ الزياعة الغوصل/ العراق. }
\end{aligned}
$$

\title{
Email: muzahim_saeed@uoimosul.edu.iq
}

\begin{abstract}
الخلاصة
تعد غابة أتروش من الغابات المختلطة التي تحتوي على العديد من أنواع الأشجار و الثجير ات الغاباتية،

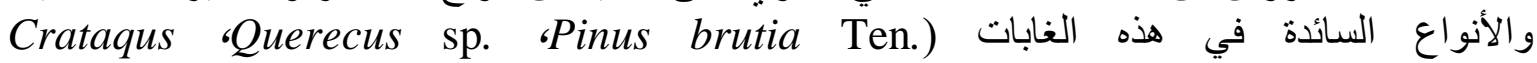
.Ficus carica L. 'Prunus amycdalus 'Rhus coriaria 'Juniperus oxycedrus 'ozaralus و Plautus spina-christi)، ومنها اخذنا مساحة (126.1821) هكتار للار اسة، وكانت عدد الفجوات فيها

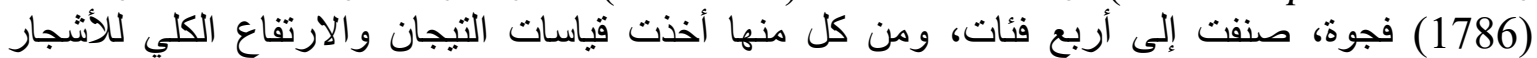

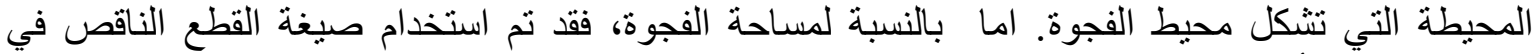

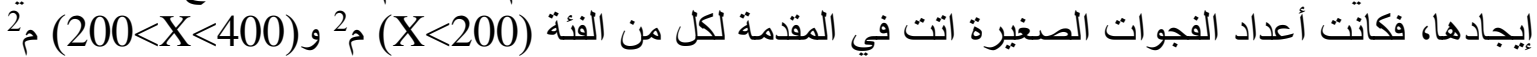

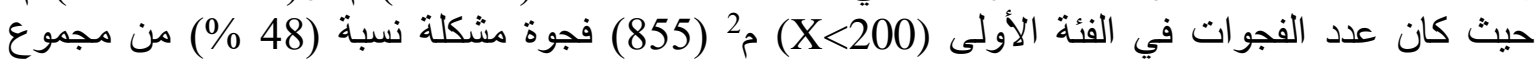

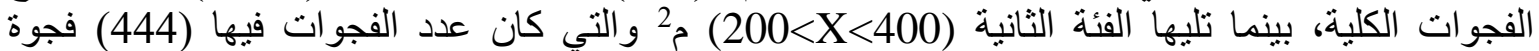

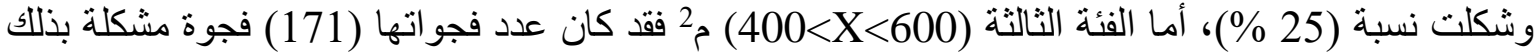

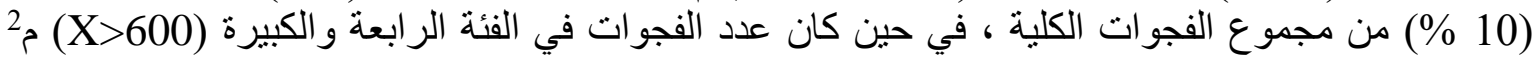

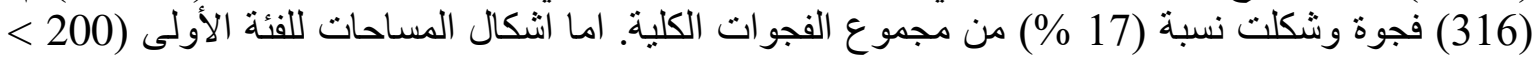

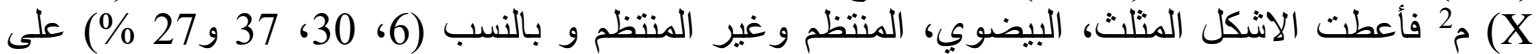

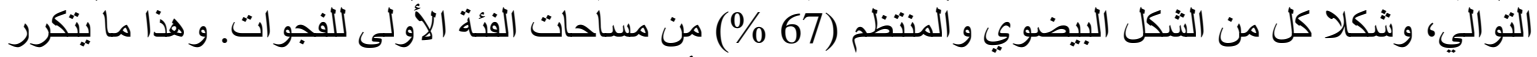
مع الفجوات ذات المساحات (9200، تشكل النسب (9، 28، 39، 24 \%) على التو الي ونجد أن الثكل البيضوي والمنتظ شكلا ما مجمو عه (67)

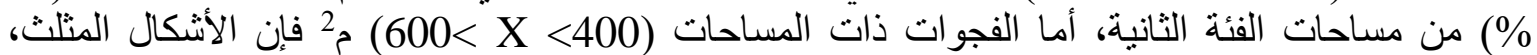

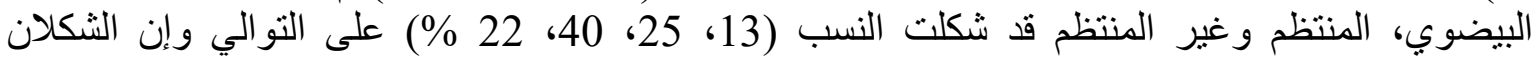

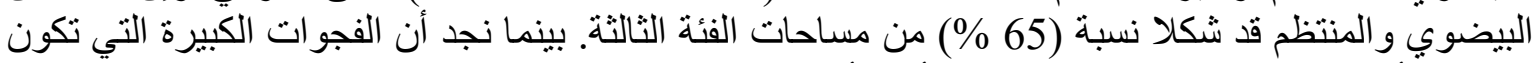

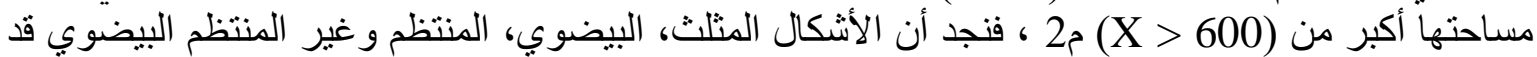

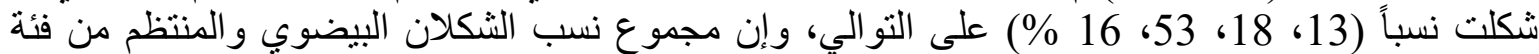

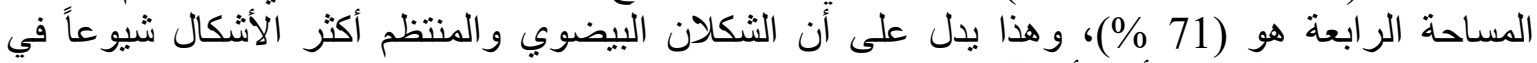

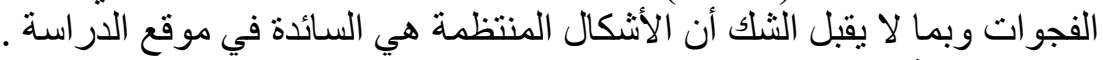

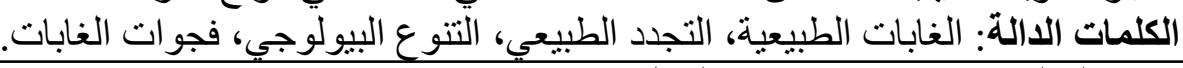

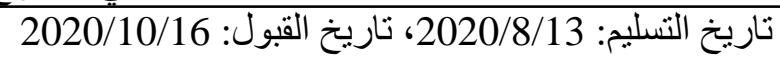

\section{REFERENCES}

Adele, M., Silvio B., Maria S. and Roberto M. (2014). A review of the roles of forest canopy gaps. Journal of Forestry Research, 25(4): 725-736.

Amiri, M., Rahmani, R. and Sagheb-Talebi K.H. (2015). Canopy gaps characteristics and structural dynamics in a natural unmanaged oriental 
beech (Fagus orientalis Lipsky) stand in the north of Iran. Caspian Journal of Environmental Sciences, 13(3): 259-274.

Betts, H.D., Brown L.J. and Stewart G.H. (2005). Forest canopy gap detection and characterization by the use of high-resolution Digital Elevation Models. New Zealand Journal of Ecology, 29(1): 95-103.

Busing, R.T. (1994). Canopy cover and tree regeneration in old-growth cove forests of the Appalachian Mountains. Vegetatio, 115(1): 19-27.

De Lima, R.A.F. (2005). Gap size measurement: the proposal of a new field method. Forest Ecology and Management, 214(1-3): 413-419.

De Lima, R.A.F., Prado P.I., Martini A.M.Z., Fonseca L.J., Gandolfi S. and Rodrigues R.R. (2013). Improving methods in gap ecology: revisiting size and shape distributions using a model selection approach. Journal of vegetation science, 24(3): 484-495.

Dusan, R., Stjepan M., Igor A. and Jurij D. (2007). Gap regeneration patterns in relationship to light heterogeneity in two old-growth beech-fir forest reserves in South East Europe. Forestry, 80(4): 431-443.

Garbarino, M., Mondino B., Lingua E.E., Nagel T.V., Duki C., Govedar Z., and Motta R. (2012). Gap disturbances and regeneration patterns in a Bosnian old-growth forest: a multispectral remote sensing and ground-based approach. Annals of Forest Science, 69: 617-625.

Guo, Y., Zhao P. and Yue M. (2019). Canopy disturbance and gap partitioning promote the persistence of a pioneer tree population in a near-climax temperate forest of the Qinling Mountains, China. Ecology and evolution, 9(13): 7676-7687.

Indra, S. and Per Christer O. (2009). Gap characteristics and their effects on regeneration, dominance and early growth of woody species. Journal of Plant Ecology, 2(1): 21-29.

Kathke, S. (2010). The role of gap dynamics for the regeneration of the natural spruce forests in the Harz Mountains. Doctoral Thesis, Faculty of Biosciences, Martin-Luther-Universität Halle-Wittenberg, Stuttgart, Germany.

Myers, N. (1997). The world's forests and their ecosystem services. Nature's Services: societal dependence on natural ecosystems, pp. 215-235. Island.

Numata, S., Yasuda M., Okuda T., Kachi N. and Supardi, M.N. (2006). Canopy gap dynamics of two different forest stands in a Malaysian lowland rain forest. Journal of Tropical Forest Science, 18(2): 109-116.

Obiri, J.A. and Lawes M.J. (2004). Chance versus determinism in canopy gap regeneration in coastal scarp forest in South Africa. Journal of Vegetation Science, 15(4): 539-547.

Pawlikowski, N.C., Coppoletta M., Knapp E. and Taylor A.H. (2019). Spatial dynamics of tree group and gap structure in an old-growth ponderosa pineCalifornia black oak forest burned by repeated wildfires. Forest ecology and management, 434: 289-302.

Sapkota, I.P. and Odén P.C. (2009). Gap characteristics and their effects on regeneration, dominance and early growth of woody species. Journal of Plant Ecology, 2(1): 21-29. 
Schnitzer, S.A., Mascaro J. and Carson W.P. (2008). Treefall gaps and the maintenance of plant species diversity in tropical forests. Treefall Gaps and Plant Species Diversity in Forestry, pp. 196-209.

Van der Meer, P.J. and Bongers F. (1996). Formation and closure of canopy gaps in the rain forest at Nouragues, French Guiana. Vegetatio, 126(2): 167-179.

Van der Meer, P.J., Bongers F., Chatrou L. and Riéra, B. (1994). Defining canopy gaps in a tropical rain forest: effects on gap size and turnover time. Acta Oecologia, 15(6): 701-714.

Zeibig, A., Diaci J. and Wagner S. (2005). Gap disturbance patterns of a Fagus sylvatica virgin forest remnant in the mountain vegetation belt of Slovenia. Forest Snow and Landscape Research, 79(1/2): 69-80. 